\title{
Microdetermination of human serum albumin by differential pulse voltammetry at a L-cysteine modified silver electrode
}

\author{
LIYUAN LU, YANQIN ZI* and HONGLING WANG \\ Department of Chemistry, Huaibei Coal Normal College, Huaibei, 235000, China \\ e-mail: ziyanqin@163.com
}

MS received 9 October 2007; revised 12 May 2008

\begin{abstract}
A simple and highly sensitive electrochemical method for the determination of human serum albumin (HSA) using differential pulse voltammetry (DPV), based on a silver electrode modified with a self-assembled monolayer of L-cysteine, was developed. L-cysteine can be modified onto a silver electrode by covalent bonding through the sulfur to give stable and long-lived chemical electrodes. This electrode showed good sensitivity, selectivity, reproducibility and time stability in the determination of trace amounts of HSA by DPV technique. The detection limit can be as low as $4 \times 10^{-17} \mathrm{~mol} / \mathrm{L}$. The optimum conditions for the determination were carefully investigated. This method had been applied to the determination of HSA in human serum samples. The results were in agreement with those given in standard method.
\end{abstract}

Keywords. Differential pulse voltammetry; self-assembled; silver electrode; L-cysteine; human serum albumin.

\section{Introduction}

The determination of protein is important in clinical diagnostics, pathology, immunology and biochemistry because it is often used as a reference for the measurements of other components in biological system. Different kinds of analytical methods including chemiluminescence method, ${ }^{1-3}$ spectrophotometric method, ${ }^{4,5}$ fluorimetric method, ${ }^{6,7}$ Rayleigh light scattering method, ${ }^{8-10}$ and electrochemical method, ${ }^{11-15}$ had been proposed in the literature. Electrochemical determination is one of the most sensitive, simple and rapid methods. However, it is difficult to determine protein with electrochemical methods, because the macromolecules are not ready to exhibit current responses due to their complex structure and deeply buried electroactive center. Meanwhile, proteins easily absorb at electrode surfaces and subsequently passivate the electrodes. ${ }^{16}$ In order to resolve this problem, a variety of chemically modified electrodes have been employed. Sun et al used organic dyes as electrochemical probes to determine the content of protein by voltammetric method. ${ }^{17-19}$ Lin and co-workers have used the silver nanoparticles modified silver electrode for the determination of hemoglobin. ${ }^{20} \mathrm{Lu}$ et al de-

\footnotetext{
*For correspondence
}

scribed an electrochemical method to determine the hemoglobin using a surfactant modified electrode. ${ }^{21}$

Since L-cysteine can be modified onto a silver electrode or gold electrode by covalent bonding through the sulfur to give stable and long-lived chemical electrodes, it has been widely applied to modify electrode for the electrochemical detection. Ma et al used the Lcysteine modified glassy carbon electrode and linear sweep stripping voltammetry to determine the content of dopamine in the presence of ascorbic acid. ${ }^{22} \mathrm{Jia}$ et al applied the L-cysteine modified gold electrode to the determination of ascorbic acid. ${ }^{23} \mathrm{Li}$ et al have reported determination of hemoglobin using the Lcysteine modified microelectrode and linear sweep voltammetry ${ }^{24}$ and $\mathrm{Gu}$ et al have used the L-cysteine modified silver microelectrode and differential pulse cathodic stripping voltammetry to determine hemoglobin. ${ }^{25}$ However, determination of HSA using the L-cysteine modified silver electrode has not been seen reported. Human serum albumin (HSA) is the most abundant protein in human blood, and it has many important physiological functions. The determination of HSA in human serum is an important item and a reference for the measurements of other components in biological system in clinical diagnosis.

In this paper, a highly sensitive electrochemical method using differential pulse voltammetry at a Lcysteine modified silver electrode for the determina- 
tion of HSA was proposed. The experimental data showed that the method had high sensitivity, good selectivity, reproducibility and time stability for the determination of HSA. This method has been applied to the determination of HSA in human serum samples and results were in agreement with those given by Bromcresol Green method.

\section{Experimental}

\subsection{Reagents and solutions}

The standard stock solution of HSA $\left(1.0 \times 10^{-6} \mathrm{~mol} / \mathrm{L}\right)$ was prepared by dissolving $0.0343 \mathrm{~g}$ of HSA (Shanghai Wenhao Biochemistry Tech. Co., Ltd., Shanghai, China) in $500 \mathrm{~mL}$ of water. The solution should be stored in a refrigerator freezer. The working solutions were obtained by diluting the stock solution with water. The saturated solution of L-cysteine (Shanghai Bo'ao Bioscience Tech. Co., Ltd., Shanghai, China) was prepared by directly dissolving it in water. NaAc-HAc buffer solutions between $\mathrm{pH} 3.6$ and 5.6 were used to adjust the $\mathrm{pH}$ of the electrolyte solutions. Three human serum samples and the standard albumin solution (presented by Huaibei Occupational disease Prevention and Cure Hospital, Huaibei, China) were diluted to suitable concentration without any purification. Double distilled, deionized water was used for the preparation of some solutions. All other chemicals were of analytical grade.

\subsection{Apparatus}

Single potential step chronoamperometry and Differential pulse voltammetry (DPV) measurements were carried out on a LK2006 electrochemical workstation (Lanlike Chemical Electron Tech. Co., Ltd., Tianjin, China). A conventional three-electrode set-up was used. The L-cysteine modified silver electrode ( $10 \mathrm{~mm}$ diameter) was used as the working electrode, a platinum wire and a saturated calomel electrode as the counter electrode and reference electrode, respectively. All the experiments were conducted at room temperature.

\subsection{Procedure}

Prior to the modification, the silver electrode was first polished with fine sand papers. Then it was polished with alumina water slurry on silk to obtain a mirror-like surface. After that, it was rinsed thoroughly with double distilled water, sonicated into water for $12 \mathrm{~min}$ and electrochemically cleaned by differential pulse voltammetric cycling from -0.2 to $0.4 \mathrm{~V}$ in $\mathrm{pH}$ 4.8 NaAc-HAc buffer solution until the base line was stable. Finally, the treated silver electrode immersed in saturated L-cysteine solution for $10 \mathrm{~h}$ and dried for $1 \mathrm{~h}$ at room temperature.

After modification, pre-accumulation was carried out by using single potential step chronoamperometry for $15 \mathrm{~min}$ at an initial potential of $-0.35 \mathrm{~V}$ and a step potential of $0.35 \mathrm{~V}$. The electrolyte solution contained $20.0 \mathrm{~mL} 5 \times 10^{-16} \mathrm{~mol} / \mathrm{L}$ standard HSA solution and $5.0 \mathrm{~mL} \mathrm{pH} 4.8 \mathrm{NaAc}-\mathrm{HAc}$ buffer solution. Then differential pulse voltammograms were recorded between -0.8 and $0.2 \mathrm{~V}$ at a scan rate of $20 \mathrm{mV} / \mathrm{s}$ and a pulse height of $30 \mathrm{mV}$. Each measurement was carried out with a new modified electrode.

\section{Results and discussion}

\subsection{Electrochemical behaviour}

DPV technique was selected for the determination of HSA due to its better accuracy and sensitivity. A pulse height of $30 \mathrm{mV}$ and a scan rate of $20 \mathrm{mV} / \mathrm{s}$ were chosen in the studies. Figure 1 showed the differential pulse voltammograms of the L-cysteine modified silver electrode in a solution of $\mathrm{NaAc}-\mathrm{HAc}$ buffer $(\mathrm{pH}=4 \cdot 8)$ as supporting electrolyte without HSA and with different concentrations of HSA. The DPV grams were taken after $3 \mathrm{~s}$ immersion of modi-

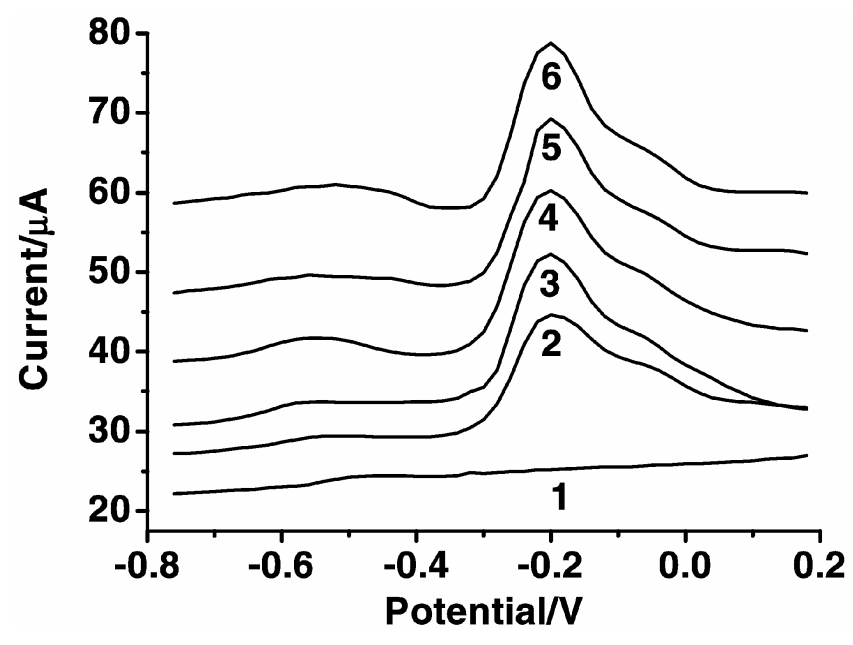

Figure 1. Differential pulse voltammograms for different concentration of HSA at a scan rate of $20 \mathrm{mV} / \mathrm{s}$ and pulse height $30 \mathrm{mV}$ : (1) $0.00 \mathrm{~mol} / \mathrm{L}$; (2) $1 \times 10^{-16} \mathrm{~mol} / \mathrm{L}$; (3) $2 \times 10^{-16} \mathrm{~mol} / \mathrm{L}$; (4) $3 \times 10^{-16} \mathrm{~mol} / \mathrm{L}$; (5) $4 \times 10^{-16} \mathrm{~mol} / \mathrm{L}$; (6) $5 \times 10^{-16} \mathrm{~mol} / \mathrm{L} \mathrm{HSA}$. 

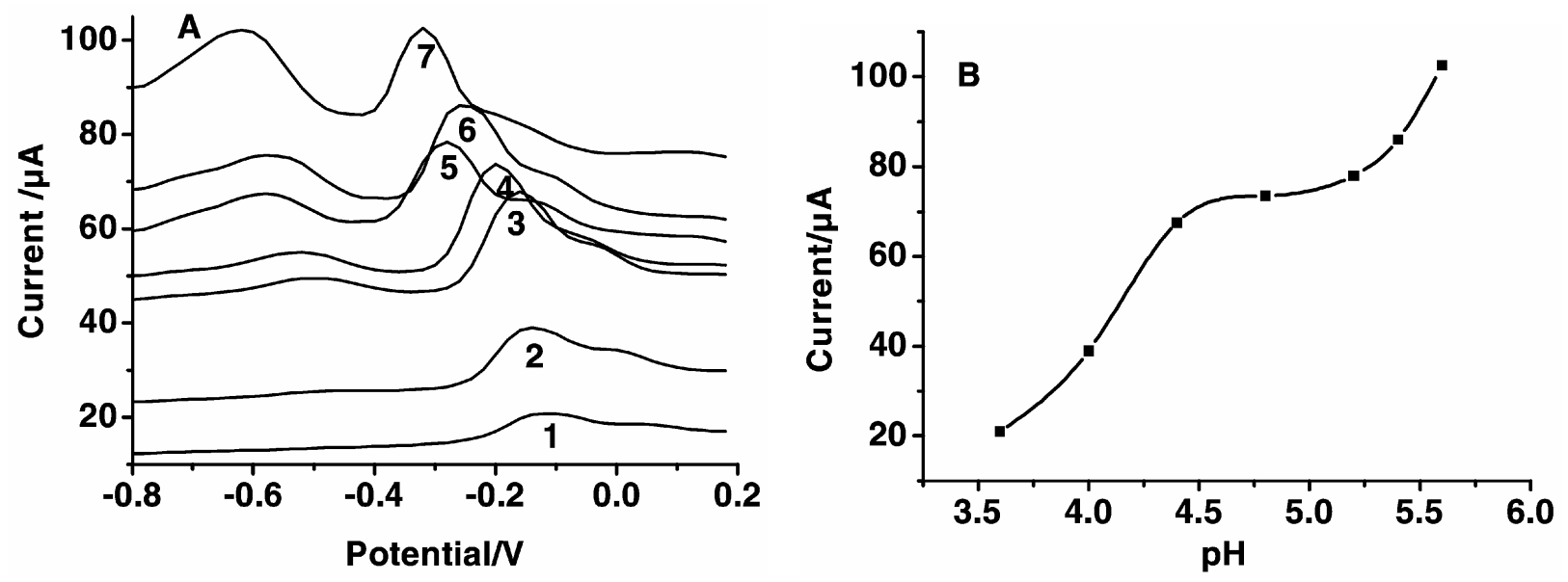

Figure 2. (A) Differential pulse voltammograms of $4 \times 10^{-16} \mathrm{~mol} / \mathrm{L}$ HSA at different $\mathrm{pH}$ values: (1) $\mathrm{pH} 3 \cdot 6$; (2) $\mathrm{pH} \mathrm{4.0;} \mathrm{(3)} \mathrm{pH} \mathrm{4.4;} \mathrm{(4)} \mathrm{pH} 4 \cdot 8$; (5) $\mathrm{pH} \mathrm{5.2;} \mathrm{(6)} \mathrm{pH} 5 \cdot 4$; (7) $\mathrm{pH} \mathrm{5.6}$, at the scan rate of $20 \mathrm{mV} / \mathrm{s}$ and $\mathrm{pulse}$ height $30 \mathrm{mV}$. (B) Plot of peak current vs $\mathrm{pH}$.

fied electrode in the solution and potential was swept from $-0.80 \mathrm{~V}$ to $0.20 \mathrm{~V}$. As can be seen from the figure, a single well-defined oxidation peak was observed at $-0.20 \mathrm{~V}$. The peak current increased with the increase of the concentration of HSA.

\subsection{Method optimization}

3.2a Influence of $p H$ : The effect of $\mathrm{pH}$ on the electrochemical response of HSA over the $\mathrm{pH}$ range 3.6 to 5.6 were examined using DPV at a scan rate of $20 \mathrm{mV} / \mathrm{s}$ and the results were shown in figure 2 . The peak currents increased and peak potential shifted toward more negative as $\mathrm{pH}$ increased (figure 2A). As can be seen from figure $2 \mathrm{~B}$, the peak current enhanced remarkably with the increase of $\mathrm{pH}$ from 3.6 to 4.4 , and then remained almost constant. After $\mathrm{pH}$ $5 \cdot 2$, the peak current increased greatly again. Meanwhile, an interferential peak at about $-0.6 \mathrm{~V}$ appeared after $\mathrm{pH} 4.4$ and the height of the interferential peak increased with the increase of $\mathrm{pH}$ (figure 2A).Taking into account these results, $\mathrm{pH} 4.8$ was chosen for the further studies.

3.2b Effect of modification time: The effect of modification time on the DPV peak current was studied in the range from 0.5 to $12 \mathrm{~h}$ using the procedure described as in $\$ 2.3$. The DPV grams were taken in the solution contained $20.0 \mathrm{~mL} 5 \times 10^{-16} \mathrm{~mol} / \mathrm{L}$ standard HSA solution and $5.0 \mathrm{~mL} \mathrm{pH} 4.8 \mathrm{NaAc}-$ HAc buffer solution. It was found that, when the modification time was $10 \mathrm{~h}$, the peak current was maximal and the interference was least. So modifi- cation time of $10 \mathrm{~h}$ was chosen as the optimal parameter in this study.

3.2c Effect of pre-accumulation time: The effect of preaccumulation time on the DPV peak current was also investigated in the range from 1 to $30 \mathrm{~min}$ in the same solution. As shown in figure 3, the peak current increased with the pre-accumulation time increased from 1 to $15 \mathrm{~min}$, while decreased for the longer time. Therefore, the optimum pre-accumulation time for the L-cysteine modified silver electrode was set at $15 \mathrm{~min}$.

\subsection{Effect of interferences}

The interferences of co-existing substances such as metal ions, amino acids, glucose, $\gamma$-globin, etc. on the determination were tested. When the concentration of the HSA was $4 \times 10^{-16} \mathrm{~mol} / \mathrm{L}$, no interferences were observed in the presence of $4 \times 10^{-12} \mathrm{~mol} / \mathrm{L}$ starch, glucose, $\gamma$-globin, $1.75 \times 10^{-12} \mathrm{~mol} / \mathrm{L}$ L-tryptophan, L-valine, $5.0 \times 10^{-7} \mathrm{~mol} / \mathrm{L}$ of $\mathrm{Ca}^{2+}, \mathrm{Mg}^{2+}, \mathrm{Co}^{2+}$ and $\mathrm{Cu}^{2+}$, respectively. It can be seen that the method has fairly good selectivity and can be applied to the direct determination of HSA in human serum without any purification.

\subsection{Reproducibility and time stability}

The stability and reproducibility of chemically modified electrode is important for its utilization in electronanalysis of HSA. In order to examine the reproducibility, a series of silver electrodes (five) with 
the same diameter $(10 \mathrm{~mm})$ prepared under the same procedure as described in \$2.3. DPV grams were recorded. The analytical solutions contained $20.0 \mathrm{~mL}$ $5 \times 10^{-16} \mathrm{~mol} / \mathrm{L}$ standard HSA solution and $5.0 \mathrm{~mL}$ known $\mathrm{pH}$ NaAc-HAc buffer solution. The mean value of HSA anodic peak current was $70.6125 \pm$ $4.5738 \mu \mathrm{A}(n=5 ; \mathrm{RSD}=5.21 \%)$.

We also studied the time stability of the L-cysteine modified silver electrode kept for a prolonged time in $\mathrm{pH} 4.8 \mathrm{NaAc}-\mathrm{HAc}$ buffer solution. The modified electrode was tested for every day and then stored at refrigerator freezer in the same buffer until the next day. After using for 150 measurements in 30 days, the electrode response was $91 \%$ of its original value. The results were shown in figure 4 , which indicated a good stability in this case.

\subsection{Application to detection of HSA}

Standard albumin solutions of different concentration were prepared to determine the linear correlation. Into a $25 \mathrm{~mL}$ flask, $20.0 \mathrm{~mL}$ known concentration standard albumin solution was added and then diluted to the mark with $\mathrm{pH} 4.8 \mathrm{NaAc}-\mathrm{HAc}$ buffer solution. After mixed well, the solution was transferred to the electrolyte cell. Under the optimized conditions, differential pulse voltammograms of each solution at the L-cysteine modified silver electrode were recorded. The peak current increased linearly with the concentration of standard albumin in the range of $5 \times 10^{-17}$ to $5 \times 10^{-16} \mathrm{~mol} / \mathrm{L}$. The calibration plot of peak current versus standard albumin concentra- tion was shown in figure 5 . The linear regression equation was: $I_{p}=42.5579+7.0035 C(R=0.9985$, where $I_{p}$ was the peak current in $\mu \mathrm{A}, C$ was the concentration of standard albumin in $10^{-16} \mathrm{~mol} / \mathrm{L}$ ). The detection limit was $4 \times 10^{-17} \mathrm{~mol} / \mathrm{L}(3 \sigma)$.

The L-cysteine-modified silver electrode was applied to determination of HSA in human serum samples by DPV under the optimized condition. In order to verify the validity of the chosen method, the standard method, Bromcresol Green (BCG) method used by hospital, was employed to analyse the same human serum samples simultaneously. Without any purification, three samples were diluted to suitable concentration with water and determined using the procedure described above. Five replicate determinations were performed for each sample. The analytical results for HSA in human serum were listed in table 1. The results obtained by the proposed electrochemical method were in good agreement with the values obtained by the BCG method.

\subsection{Interaction mechanisms}

L-cysteine is a sulfur containing amino acid and can be modified onto a silver electrode by covalent bonding through the sulfur. In a $\mathrm{pH} 4.8 \mathrm{NaAc}-\mathrm{HAc}$ buffer solution, the L-cysteine is positively charged (the $\mathrm{pI}$ is 5.05$)$ while the HSA is negatively charged $\left(-\mathrm{COO}^{-}\right)$ at the remaining groups of amino acid on its single peptide chain of HSA (the pI is 4.7). So the HSA can be attracted by the L-cysteine via at first electro-

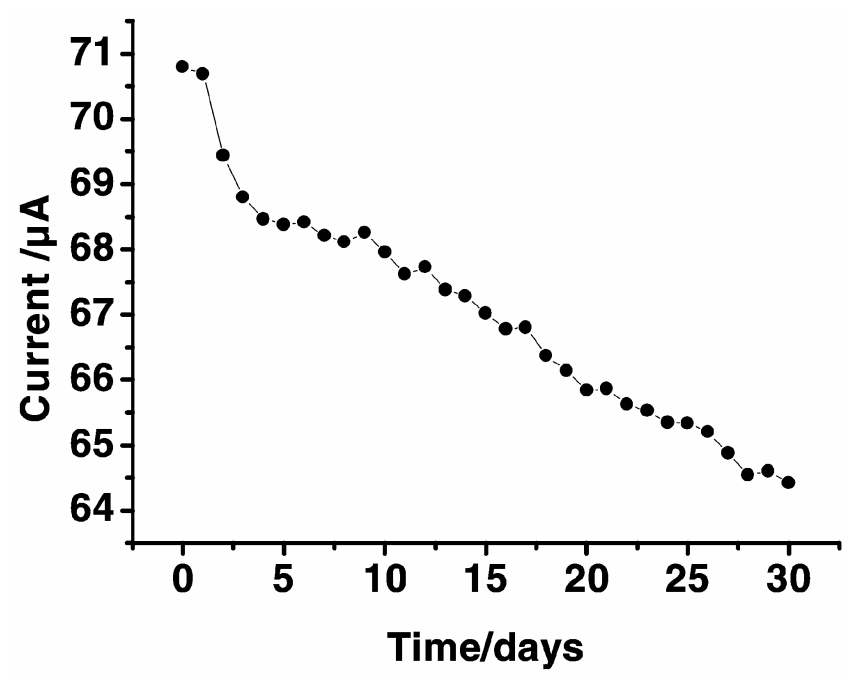

Figure 4. Time stability measurement at the L-cysteine modified silver electrode using DPV in $4 \times 10^{-16} \mathrm{~mol} / \mathrm{L}$ HSA solution.

Figure 3. Effect of pre-accumulation time on the peak current of concentration $4 \times 10^{-16} \mathrm{~mol} / \mathrm{L}$. 
Table 1. Determination results of HSA in three samples $(n=5)$.

\begin{tabular}{lcccc}
\hline Sample & $\begin{array}{c}\text { Proposed method } \\
(\mathrm{g} / \mathrm{L})\end{array}$ & $\begin{array}{c}\text { BCG method } \\
(\mathrm{g} / \mathrm{L})\end{array}$ & RSD $(\%)$ & $\begin{array}{c}\text { Relative error } \\
(\%)\end{array}$ \\
\hline 1 & $40 \cdot 3$ & $42 \cdot 2$ & 3.53 & 4.50 \\
2 & 47.1 & $45 \cdot 3$ & 3.98 & 3.97 \\
3 & 45.4 & 46.1 & 2.71 & 1.56 \\
\hline
\end{tabular}

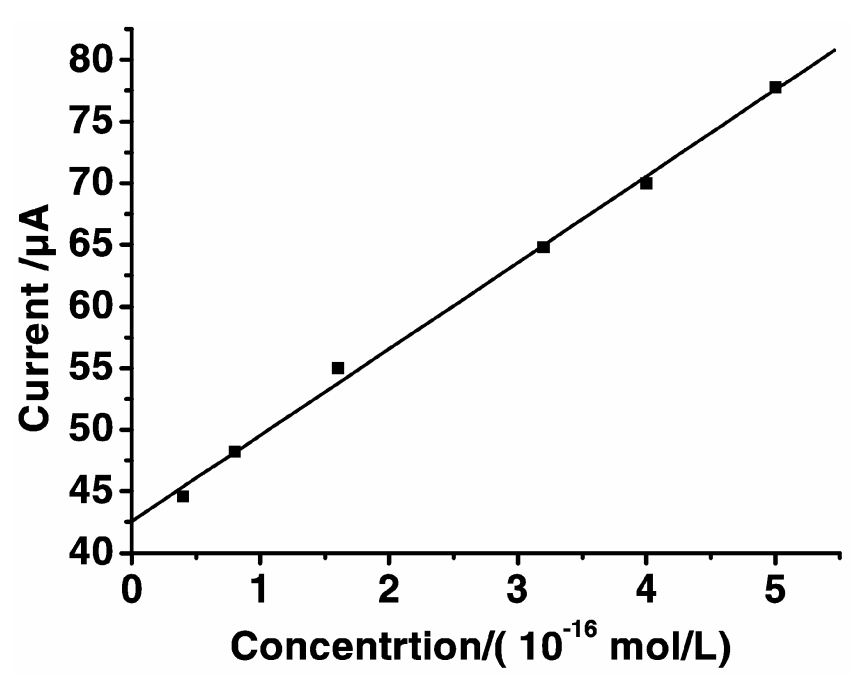

Figure 5. Standard curve for the determination of HSA.

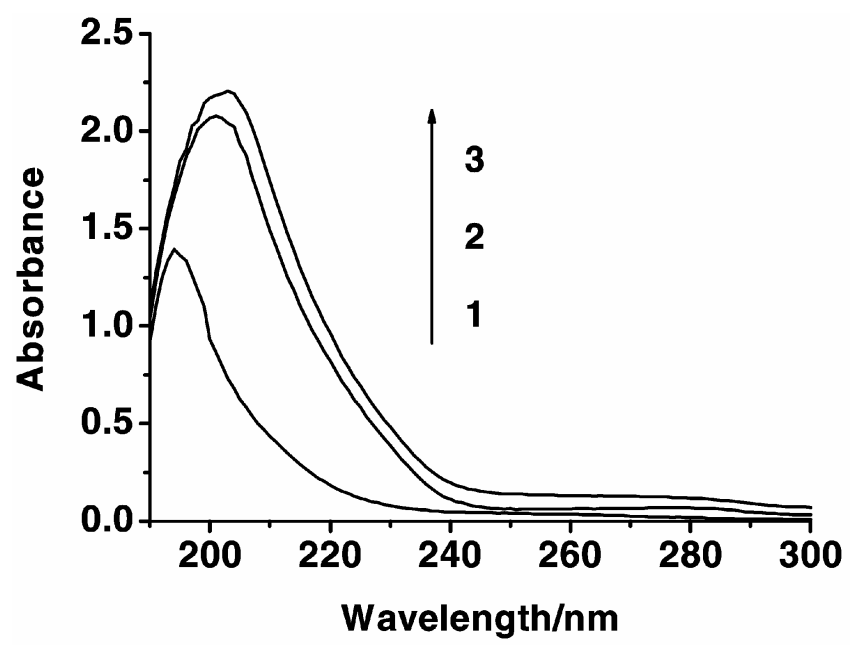

Figure 6. Absorption spectra of: (1) $80 \mathrm{mg} / \mathrm{L}$ L-cysteine; (2) $80 \mathrm{mg} / \mathrm{L} \mathrm{HSA}$; (3) $80 \mathrm{mg} / \mathrm{L}$ L-cysteine $+80 \mathrm{mg} / \mathrm{L}$ HSA.

static attraction. Then the HSA combines to the Lcysteine via electrostatic attraction, hydrogen bond, and hydrophobic bond. Figure 6 showed the UV-Vis absorption spectra of L-cysteine with HSA in a $\mathrm{pH}$ 4.8 NaAc-HAc buffer solution. L-cysteine had the

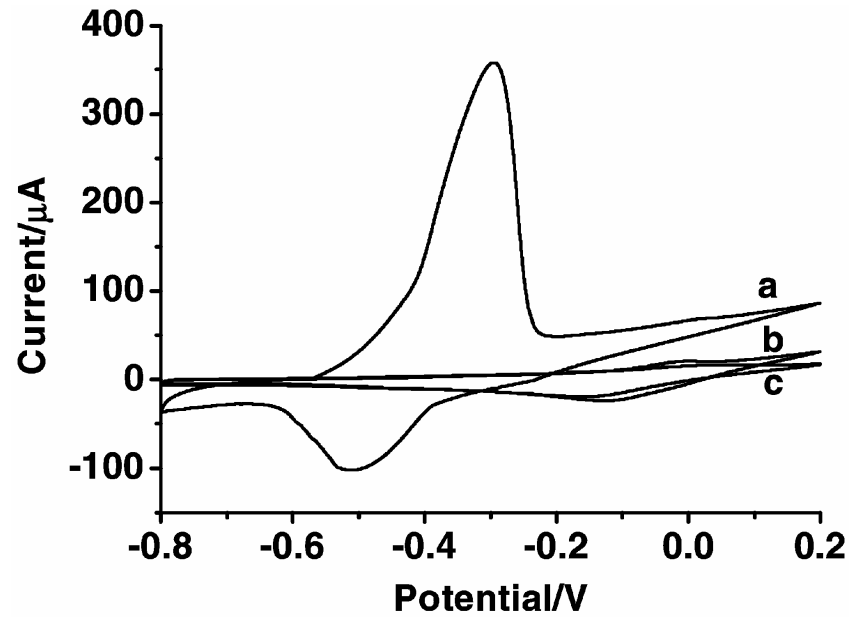

Figure 7. Cyclic voltammograms of (scan rate: $200 \mathrm{mVs}^{-1}$ ): (a) $1 \times 10^{-9} \mathrm{~mol} / \mathrm{L} \mathrm{HSA}$ at the L-cysteine modified silver electrode; (b) $1 \times 10^{-9} \mathrm{~mol} / \mathrm{L} \mathrm{HSA}$ at the bare silver electrode; (c) $0.00 \mathrm{~mol} / \mathrm{L} \mathrm{HSA}$ at the L-cysteine modified silver electrode.

maximum absorption at $194 \mathrm{~nm}$, and after the interaction with HSA the maximum absorption number moved to $202 \mathrm{~nm}$ with an increase of the absorbance. The observed hyperchromicity and red shift indicated that there was an interaction between the L-cysteine and HSA. ${ }^{26}$ It was the coordination of electrostatic attraction, hydrogen bond and hydrophobic bond that make it possible to transfer the electron of the HSA to the surface of the working electrode.

Figure 7 showed the cyclic voltammograms of the L-cysteine modified silver electrode (a) and the bare silver electrode (b) with HSA, and the L-cysteine modified silver electrode without HSA (c) in the $\mathrm{NaAc}-\mathrm{HAc}$ solution. The $\mathrm{CV}$ grams were taken after $2 \mathrm{~s}$ immersion of modified electrode in the solution and potential was swept from $-0.8 \mathrm{~V}$ to $0.2 \mathrm{~V}$ with scan rate of $50 \mathrm{mV} / \mathrm{s}$. As can be seen from figure 7 , a couple of very small redox peaks were observed at about $0.00 \mathrm{~V}$ and $-0 \cdot 10 \mathrm{~V}$ in the scan potential range at the bare electrode (curve b), which indicated that HSA has electroactivity. HSA is a kind of protein without metal ion. Based on the theory of Stank- 
ovich and $B a r d,{ }^{27}$ the redox occurred on the $\mathrm{S}-\mathrm{S}$ bonds of HSA peptide chain. After modification, well-defined anodic wave and cathodic wave were observed at about $-0.29 \mathrm{~V}$ and $-0.50 \mathrm{~V}$, and the corresponding peak currents greatly increased (curve a). In addition, the potentials of anodic and cathodic peaks shifted towards negative value, which indicated that the L-cysteine monolayer accelerate electron transfer via interaction between the L-cysteine and HSA.

\section{Conclusions}

In this work, a highly sensitive electrochemical method for determination of HSA using DPV at an L-cysteine modified silver electrode was proposed. The detection limit was $4 \times 10^{-17} \mathrm{~mol} / \mathrm{L}$ and much lower than those reported by other electrochemical methods. A modification time of $10 \mathrm{~h}$, pre-accumulation time of $15 \mathrm{~min}$, scan rate of $20 \mathrm{mV} / \mathrm{s}$, pulse height $30 \mathrm{mV}$ and $\mathrm{pH} 4.8 \mathrm{NaAc}-\mathrm{HAc}$ buffer were chosen as the optimal conditions. Moreover, this method has a good selectivity, reproducibility, time stability, and has been applied to determination of HSA in human serum without any purification. The results were in good agreement with the BCG method.

\section{Acknowledgements}

This work was supported by the Natural Science Foundation of Anhui province (No. 2006KJ128B).

\section{References}

1. Joo I S, Lee S H, Suh J K and Kim C J 2002 J. Anal. Sci. 17117

2. Hara T, Yokogi J, Okamura S, Kato S and Nakajima R 1993 J. Chromatog. A652 361

3. Li Z, Li K and Tong S 1998 Microchem. J. 60217
4. Wei Y J, Li K A and Tong S Y 1996 J. Talanta. 431

5. Zhang L, Li N, Zhao F L and Li K A 2004 J. Anal. Sci. 20445

6. Lee S H, Suh J K and Li M 2003 J. Bull. Korean Chem. Soc. 2445

7. Li D H, Yang H H, Zhen H, Fang Y, Zhu Q Z and Xu J G 1999 J. Anal. Chim. Acta 401185

8. Ma C, Li C and Tong S 1997 J. Anal. Chim. Acta 338 255

9. Huang C, Li Y, Mao J and Tan D 1998 J. Analyst. 1231401

10. Yao G, Li K and Tong S 1999 J. Anal. Chim. Acta 398319

11. Wang J, Vila V and Tapia T $1988 \mathrm{~J}$. Bioeletrochem. Bioenerg. 1939

12. Estela J M, Tomas C, Cladera A and Cerda V 1995 J. Crit. Rev. Anal. Chem. 25991

13. Honeychurch M J and Ridd M J 1996 J. Electroanalysis 8654

14. Honeychurch M J and Ridd M J 1996 J. Electroanalysis. 849

15. Tomschik M, Havran L, Fojta M and Palecek E 1998 J. Electroanalysis $\mathbf{1 0} 403$

16. Anderson J L, Bowden E F and Pickup P G $1996 \mathrm{~J}$. Anal. Chem. 68 413R

17. Sun W, Han J Y, Yong R and Jiao K 2006 J. Braz. Chem. Soc. 17510

18. Sun W, Han J Y, Jiao K and Lu L D 2006 Chin. J. Anal. Sci. 22145

19. Sun W, Han J Y and Jiao K 2005 Chin. J. Anal. Lab. 2459

20. Lin L, Qiu P H, Yang L Z and Cao X N 2006 Chin. J. Anal. Chem. 3431

21. Lu Z, Huang Q and Rusling J F 1997 J. Electroanal. Chem. 42359

22. Ma X Y, Chao Z, Li X, Xu H Y and Zhang G R 2006 Chin. J. South Med. Univ. 26648

23. Jia L, Zhen Y, Zhang X H and Wang S F 2004 Chin. J. Hubei Univ. (Nat. Sci. Edit.) 2648

24. Li G, Fang H, Long Y, Chen H and Zhu D $1996 J$. Anal. Lett. 291273

25. Gu K, Zhu J J and Chen H Y 1999 Chin. J. Anal. Chem. 271172

26. Long E C and Barton J K 1990 Acc. Chem. Res. 23 271

27. Stankovich M T and Bard A J 1978 J. Electroanal. Chem. 86189 